\title{
A Study of Shopping Day Among College Students Between China and America
}

\author{
Ming Xu \\ Foreign Language School \\ Jilin Institute of Chemical Technology \\ Jilin, China
}

\begin{abstract}
Cultural differences exist in many aspects between China and America which involve a wide variety of study. However, as the world's two largest economic groups, China and America have their own shopping cultures and shopping day which largely boost their sales volumes. Shopping, a fundamental action, is really fashionable among the young adults especially in November. Each year DoubleEleven is quite popular whereas in the United States, there is a quite similar shopping day - Black Friday, that is also enjoying huge influence. In terms of these two shopping days, their own history and individuals' consuming patterns are different. This paper will focus on the study of shopping day between China and America and take college students an research object.
\end{abstract}

Keywords-double-eleven; Black Friday; shopping; college student

\section{INTRODUCTION}

Shopping plays a necessary part in each person's life which we are unable to escape from in order to survive. So that is the fundamental role of shopping. However, besides it, shopping has also become a fashion. Thus the new trend of shopping came into being such as distinctive shopping festivals. Basically, shopping days enjoy much attention both in China and America. This paper will focus on these shopping days in two countries.

\section{ThE INTRODUCTION OF SHOPPING DAY BETWEEN CHINA AND AMERICA}

\section{A. Shopping Day in China}

In China there are two big sales days: 6.18 and 11.11. These events have turned into absolutely massive online sales carnivals. The shopping festival offers Chinese consumers the largest promotion every year. Retailers and ecommerce companies rely a lot on this annual promotion for reaching huge revenues growth. And they have really been built as consumers' days to buy something for themselves that make them happy. 6.18 shopping carnival was first established in June 18th, 2003 that was also the foundation date of JD Mall. So in the beginning, 6.18 it was just an anniversary celebration until recent years, it has become a shopping day compared with Double Eleven. While 11.11(Double-Eleven) is another shopping carnival set by
Taobao Mall in 2009 which has enjoyed large attention since the first year till now. 11.11 falling on November 11th is also called the Singles' Day as the date of 11.11 consists four ones. In Chinese culture, it describes 1 as single and describes 2 as couples. Compared with the couples, the singles are vulnerable groups from the humor sense. So the e-commerce platform seizes the opportunities skillfully to provide privilege to these singles, and give great promotion on this day. On the other hand, it is reported that DoubleEleven is a certain day after the national holiday and before the New Year to satisfy their needs of entertainment to relax themselves. At the same time the weather becomes colder, so people have to purchase the clothes during this period of time. Therefore, Double-Eleven has appeared and got popular. A number of commodities across all product lines will be on sale on shopping day. People are willing to stay up because as soon as the clock strikes twelve and then all of discounts suddenly kick in. Products sell out rather fast that is the reason why people can't wait till the next morning. In the year 2018, the official statistical data published by JD and Tmall, indicated 201.5 billion RMB in sales during 6.18 while 213.5 billion RMB in sales during Double-Eleven.

\section{B. Shopping Day in America}

Each year, after Thanksgiving Day, there are two biggest shopping days of the year around the corner in America. One is Black Friday, and the other one is Cyber Monday. Black Friday is an in-store shopping holiday which is on the fourth Friday in November, just a day after Thanksgiving. Because the day after Thanksgiving was typically a day off which allows Christmas shoppers to get a jump-start on their gift buying. Retail stores took advantage of this opportunity by holding major sales, which in turn helped them tip their annual sales numbers into "the black" (meaning out of "the red," which is accounting parlance for losing money). But the real story is a bit different. According to history.com, the Philadelphia police force used the term "Black Friday" in response to the chaotic traffic caused not by big sales, but by massive attendance for the Army-Navy football game held annually on the Saturday after Thanksgiving. It was only in the 1980s that retailers began to truly embrace the day for sale purposes. Nowadays, on Black Friday, shopping malls usually open at crack of dawn but some even open at midnight in order to beat the crowds. Consumers hope to get products of promotion. 
Cyber Monday is the Monday following Thanksgiving weekend which is as the day to shop online. The name of Cyber Monday has the following reasons. In old days, the Internet was often referred to as "cyberspace".

And in the early days of online shopping, Monday proved a lucrative day for online stores because it turns out people like to shop while they're at the office, using fast computers and high-speed connections. For cyber Monday, it is a better day to shop for tech deals and smaller gifts. For Black Friday, this doorbuster will typically exceed anything you will find online. It is said, the college students tend to prefer online shopping, and while the deals themselves might not be quite as good on Cyber Monday as on Black Friday. The former tends to drive more actual revenue for sellers. In 2018, CM sales hit $\$ 7.9$ billion in the US, a new record and a solid increase over 2017. It also edged out BF's $\$ 6.2$ billion, which was also a record.

\section{THE FEATURES OF SHOPPING DAY BETWEEN CHINA AND AMERICA}

Both 6.18 and 11.11 are online sales event not physically in the shopping mall. But Black Friday is about shop's opening promotion. From the aspect of safety, online shopping is safer and much more convenient. Consumers just click the mouse to add the goods to shopping cart and then pay off. In general, there are mainly four steps to get what you want: purchase, inspection, shipment, delivery.

In China, to promote the sales, some brands are taking it to the next level. There are different levels of how you can engage with gifting product and to the other extreme where you are actually collaborating to create products. They have a lot of parties related to what the brands are doing. They do a lot of cross-collaborations during the sales day and have fashion shows where they have a catwalk and consumers are able to buy the clothing that the models are wearing on the catwalk. Or a retailer uses the sales day to introduce the new technology. So if people look at Alibaba and JD (or some of these other players), they have invested very heavily in improving logistics and infrastructure. China has some of the first automated warehouses. So the demand is absolutely there for rather fast delivery. The thing with sales days is so successful and consumers like a good deal. This is particularly powerful in China's market. A new app could have tens of millions or hundred million users. So the ability to recommend really relevant content is much easier than it was.

There is a bit of that same frenzy that shoppers get with Christmas shopping. Stores do propaganda to make people experience FOMO: fear of missing out. No matter how freezing the weather is, people attracted by the big discount would rather wait outsides even at midnight to beat the crowds on Friday. Actually, there exist several kinds of incidents on Black Friday. They are trampling, stabbing, shooting, pepper spray, car and fight.

According to the data in 2008, the trampling ranked No.1 among the incident with $30 \%$. By the time stores unlock their doors, crowds have already gathered. When everyone runs in at once, of course some people are going to trip or they are pushed over in the rush. Car incidents are another notable type. While most of the other incident types seem obvious results of people arguing or fighting, car incidents can happen because of overcrowded parking lots combined with customers walking to and from their vehicles. Compared with Black Friday, Cyber Monday will help to reduce the pressure of the shopping season. In reality, Cyber Monday has come to replace Black Friday as the biggest shopping event in the US. DealNews reported that last year's Cyber Monday average savings (per user, per purchase) peaked at $21 \%$, while Black Friday savings peaked at $18.5 \%$.

\section{FACTORS DRIVING COLLEGE STUdENTS' EXCESSIVE CONSUMPTION}

There are a variety of factors that drive consumption included on shopping days. This paper will especially focus on the shoppers of college students.

\section{A. Commercial Advertising}

Nowadays, we are living in an era of rapid economic development. In such a modern society, advertising has really become more and more pervasive in our daily life. The fast growth of international exchanges and acute competition has triggered an increasing need for advertising. In this sense, advertising will be commented to be more persuasive, intentional and constructive with its purpose to maneuver the mind and behavior of its target audience. The language of advertising is usually creative, comprehensive and humorous. Some ones even have celebrity endorsement to attract the young college consumers to create an illusion that people using the product can be like them. Under this kind of circumstance, college students are available to see advertisements almost everywhere in the public places or the TV and website they browse or the APP they use, such as Wechat, micro blog, Taobao, Pinduoduo, Weipinhui and so on. These advertisers are ceaselessly telling students to spend, spend, spend. Recently, marketing is getting more complicated for shopping day going beyond advertisements. Live streaming and short videos are gaining popularity as an important channel for sales conversions. Due to lacking of social experience, college students are easy to be trapped into this kind of consumption with the influence of advertising.

\section{B. Tight Money, Easy Credit}

During the transition from adolescent to adulthood, college students have the right to consume freely. Instead of managing their money prudently, they even spend recklessly. If their expenses exceed savings, they may probably find out other ways to meet their needs. For someone, asking money from parents is the easiest way, while the other students are not available to do it likewise.

Credit is the fastest way to satisfy their desires whose procedures are not complicated. An ID card is enough for college students to borrow a loan. Besides debt, they can also choose installment to consume first and pay off later. Many applications will provide such kind of payment with lower interest rates, such as Mayihuabei and JD Baitiao. Although 
actually more painful to hand the cash than swipe a card or click the screen of smartphone. vicious cycle of paying the minimum balance.

\section{Conspicuous Consumption}

For college students, some things they buy for survival. Some things they buy for making themselves comfortable. But some things they buy not because they are necessary, but because they want to show off their success as a particular sort of person or just keep up with the Joneses. So the type of expensive brand-name stuffs could meet this purpose. This is called "conspicuous consumption". This mentality comes from peer pressure. Seeing or hearing what the classmates or friends have, they feel the need to have one and imitate them in all manners of behavior and even to be better than the others. It is a state of success. American economist Thorstein Veblen popularized the concept of "conspicuous consumption". When consumption is no longer driven solely by need, it becomes a way of making a statement that people can enjoy life on their terms. Simple pleasures - a smartphone, designer clothing — become statements of personal identity.

\section{Suggestions For COLlEGE StUdEnTs' REASONABLE CONSUMPTION}

When college students are facing the influential shopping days, they are easy to be trapped into it and spend much money. The expensive goodies seem nice, but in fact they are unnecessary from a practical perspective. They will only make you satisfied for a very short period of time before the next "must-have" item rolls around. Here are suggestions about avoiding unnecessary expenses.

\section{A. Budgeting}

Budgeting is the first thing the college students need to settle before they do anything else. For the certain things, such as garment, shoes and makeups for female students, just start wondering if what you're buying is really necessary. If you are investing in a luxury garment, do remember that they have the power to make you crazy and even destroy you. But for the things that you really need, you had better check the discount in advance and make sure that those items are cheaper on shopping days. Managing money, prioritizing expenses can be tricky. They will take a bit of practice, but it will make college students' life much less stressful. They can try to use an excel spreadsheet to help with expenses by inserting all the items that they must spend on in a monthly basis and then regularly track. This will help students manage money better.

\section{B. Using Cash}

Using cash is a sensible choice not only on shopping days, but also in our daily life. China's online payment is quite successful in our society with a great number of users especially among young adults. When college students go out somewhere to eat or buy groceries or just buy things in general, try to use cold hard cash instead of bank card or online payment. When using cash, you will have an emotional attachment to the physical material paper and it's

\section{Safety First, Shopping Second}

Shopping is less important than personal security. If you are in America on Black Friday, you had better try to stay away from the very crowded area to avoid from been trampling. Be careful about the deceptive advertising and malicious adware and prevent yourself from buying counterfeit and shoddy products. College students had better not touch debt which will even interrupt your normal life if you can't pay off on time. Some college students had committed suicide facing the loan with a higher interest. For online shopping, it is a bug business with so much money being exchanged. It's no surprise that many criminals target online shoppers. So be sure to use strong password when you are paying for the goods and avoid malware

\section{CONCLUSION}

We are living in a big world and enjoying the different cultures but also a small world through Internet connection. Shopping, as the most common and necessary action around us, has no too much differences itself. But is has meaning for us to study the consumption psychology and the tactics to address. This paper introduced the shopping days in China and the United States so as to attract the attention on college students' consumption and help them avoid the shopping traps.

\section{REFERENCES} the United States [J]. Overseas English,2018(23):249-250.

[2] Jenny Hu. Chinese Consumers Continue to Enjoy "Black Friday"[J]. China's Foreign Trade,2016(06):46-48.
[1] XuMing. An Analysis about Shopping Festival between China and 